\title{
A Psychometric Evaluation of Skill Clusters and Practices Used by Highly Effective Executive Presenters
}

\author{
Augustine C. Arize ${ }^{1}$, Scott Liu ${ }^{2}$, Solomon Nyaanga ${ }^{3}$ \& John Malindretos ${ }^{4}$ \\ ${ }^{1}$ Regents Professor, Department of Economics and Finance, College of Business, Texas A\&M University, USA \\ 2 Associate Dean, Global Programs, Executive Director, Center for International Business Studies, School of \\ Management, New York Institute of Technology, USA \\ ${ }^{3}$ Department of Management and Marketing, Cotsakos College of Businessm William Paterson University, USA \\ 4 Department of Economics, Finance and Global Business, Cotsakos College of Business, William Paterson \\ University, USA
}

Received: May 9, 2017

Accepted: May 29, 2017

Online Published: October 17, 2017

doi:10.5430/ijfr.v8n4p115

URL: https://doi.org/10.5430/ijfr.v8n4p115

\begin{abstract}
The present paper is an evaluation of those skill clusters and practices that are associated with superior ratings of executive presentation skills. It focuses on improving executive presentation skills. It explains the basics of oral presentation skills in general that apply across domains including that of business and management. Six sets practices were found to be characteristic of effective executive business presentation: the preparation, the delivery, and the questions and answers that follow the delivery. As Pappas and Hendricks (2000) and DiStanza, and Legge, 2002 found that an effective executive presentation includes the presenter's mastery and skill in technical content, organization, delivery and relating to the audience. Effective presenters have must be proficient at collecting, selecting, organizing, and illustrating their data, and have to be acutely aware of the purpose of their presentation, and the needs and interests of the audience. So, what distinguishes an executive presentation from other forms of oral communication is the context (environment), the content and the audience. The ingredients of an effective executive presentation are more or less the same as those of any other types of face-to-face presentations. Hence, although this article is focused on helping executives develop and more effectively use their oral presentation skills and practices, our framework can be of used by others who want to be effective public speakers.
\end{abstract}

\section{Introduction and Review of Relevant Literature}

Effective presentations and public speaking skills are very useful in many aspects of work and life. Effective presentations and public speaking skills have been shown to be very important in business, sales and selling, training, teaching, lecturing and generally entertaining an audience. Developing the confidence and capability to give good executive presentations, and to stand up in front of an audience and speak well, are also extremely helpful competencies for self-development too. The importance of business communication skills has received much attention during the last 60 years (Butler, 1960, Downs and Conrad, 1982, Drucker, 1954, Hildebrandt, Bond, Miller and Swinyard, 1982, Hunter, 1983, McNaughton, 1963, Warlum, 1988, Montzberg, 1989, Scudder and Guinan, 1989). There is also increasing evidence that executive communication skills have become integrated into and become an important element in the MBA and EMBA Program curriculum (Campbell, Mothersbaugh, etal, 2001, Ober, 1987, Sorenson, Savage and Oren, 1990, Leeds, Raven, and Brawley, 2007).

Academics and practitioners have long agreed that communication skills are linked to professional effectiveness. Russ (2009) concluded that faculty must provide students with the communication skills demanded by employers. Campbell eta I (2001) found that oral presentations skills must be mastered to have a successful professional life; Grez, Valcke, and Roozen (2009) concurred that higher education should address this skill as a key competency and Kennedy (2007) noted research from both business leaders and alumni claiming college graduates often lack adequate oral communication skills.

\section{Literature Review}

There is plethora of research, writing and books on effective oral presentation skills, precise definitions of "executive presentation or "oral" presentation are hard to find. A literature search for publications that provide empirical or 
statistical data on specific features of oral presentations or public speaking does not reveal a rich set of characteristics. Oomkes (2000), for example describes public speaking as a "limited interaction because only one person is speaking and others are listening". However, his definition is focused on formal presentations to large audiences. This paper does not discuss whether the features or interaction between a presenter and the audience is the same for presentations to small groups. Schultz von Thun (1998) and Wiertzsema and Jansen (2004) describe three purposes of oral presentations; persuading, informing and relating. However, neither paper provides an operational definition or construct of oral presentations or presentation skills. Van Merrienboer, Van der Kklink and Hendriks (2002) go one step further in their definition of oral communication competence. According to these authors, specificity (or context relevance), integration (structure) and durability (retention of the message, are three factors that result in effective oral presentations. Bastiaens, Kirschner, and van der Vleutren (2007) define oral presentation competence as "the combination of knowledge, skills and attitudes needed to speak in public in order to inform, to self-express, to relate, and to persuade".

Based on our review of academic research, professional business publications and "self-help" books several, these various sources differ in how effective presentations and effective presentation skills are defined. Carnegie (1976) describes effective presentation skills based how to develop poise, gain self- confidence, improve your memory, make your meaning clear, begin and end your talk, generate and maintain the interest and charm your audience, improve your diction, and win an argument without hurting people. Carnegie and Carnegie (1977) also focus on using presentations to win others over to your point of view by maximizing impact as a speaker. Gaulke (1996) offers an inventory of 101 audience-tested anecdotes, experiences, quotes, and insights that illustrate effective oral communication. Wilder (1994) presents 10 steps that help you to "sell your ideas". Dowis (1999) discusses how factors that tend to reduce the effectiveness of oral presentations. He indicates that one's impact on an audience is lost if your speech is rambling, illogical, and boring. Zelazny (1999) describes how humor and visuals, among other things, can make presentation more effective. Detz (2000) concentrates on the "process" that is that result in more effective oral presentations; these include, initial preparation, organization, delivery skills, and the use of technology. Booher (2002) introduces the basics that you must master, along with advanced techniques for fine-tuning your delivery and maximizing your impact on the audience.

The author attempts to teach you how to (i) establish rapport with your audience, (ii) speak with passion, persuasion, proper pacing, and punch, (iii) organize your ideas and plan your structure quickly for optimum effect, (iv) match your delivery style to your content, audience, and purpose, (v) add interactivity to your presentation, and (vi) use multimedia to engage your audience. Kaye, et al. (2002) help you take your career to the next level by communicating like a seasoned business leader. Jeary (2003) describes eight "secrets" that you can practice to achieve dramatic results. In his opinion, speaking is more a skill than a talent and requires techniques such as reciprocation, authority, scarcity, and tactics like knowing your audience and overcoming anxiety. Leech (2004) provides practical advice on the best ways of communicating information. His work is focused on helping you make your case using persuasive supporting materials that illuminate and inspire, win over the audience with persuasive evidence, and create a positive impression through voice and language, both verbal and nonverbal. Mortensen (2004) provides strategies for persuading, influencing, and motivating others. Jacobi and Randall (2000) provide advice on how to develop a dynamic speaking style to project power, confidence and persuasiveness; because your success depends on the confidence and conviction you project. They guarantee that your voice can make the difference between prosperity and failure. Grant-Williams (2002) described how to employ positive vocal techniques and become a more confident presenter. Finlayson (2001) rivets attention on questioning techniques. He argues that it is not enough to just ask questions; it is important to know which questions to ask and how to ask them. When you master the art of asking smart, meaningful questions, you not only make an excellent impression, but also improve your performance. Williams (2004) explains the significance of strong, clear feedback, which is a critical nutrient for the presenter. Wempen (2004) and Atkinson (2005) discuss powerful, practical, and easy to apply techniques for PowerPoint.

Looked at from another perspective, the literature on presentation skills has three broad focus points: the process, the nature, and the impact. For example, Bienvenu (1999) and Diresta (1998) tell you how to create and deliver your message with power and punch. Peoples (1992) and Leech (2004) have proven practical advice on how to communicate the essential information. Kalish (1997), Diresta (1998) and Tisdale (2005) have the recipe for "terrific", "knockout", and "effective" presentations respectively. However, · whether the book is process-oriented or nature-oriented, the ultimate objective is to help the presenter communicate effectively with the audience. That is why Stevenson (2003) and Atkinson (2005) aim at capturing the audience attention, inspiring their action, and producing results. Sampson (2003) advocates the use of creative ideas to influence the listeners. Pfarrer (1998) and 
McCarthy and Hatcher (2002a, 2002b) view presentations as the art of persuasion. In Weissman's (2003) opinion, the goal of a presentation is to connect with the audience and win them.

Of all the books and articles mentioned above, only some (Gaulke, 1996, Witherspoon and White, 1997; Pfarrer, 1998; Rotondo and Rotondo, 2001; Sampson, 2003; Stevenson, 2003; and Tisdale, 2005) have been written for business people in view, and Villata's (2003) has been written with medical presenters in mind. One of the goals of the present study was to determine if there were constructs and measures of the presentation practices and skills used by highly effective managers and executives. In our review of over 500 research studies conducted between 1960 and 2011, there were numerous anecdotal and conceptual papers about the characteristics of effective executive presentations. However, we failed to identify any statistical studies that focused specifically on psychometrically valid or reliable measures of executive presentation skills and practices.

\section{Specific Studies of Presentation Skills and Practices in Educational Settings}

In general, the literature focuses on three areas: a) studies and research on basic oral presentations skills and competencies or studies that focus on understanding or evaluating specific aspect of the skill, (b) literature that is basically process-oriented, nature-oriented, or impact-oriented, and (c) literature written for general presenters especially for business executives and managers. Expectedly, all books on the topic profess that if you gain some good advice about how to make presentations, you can overcome your fears and become more effective. The following is a review of effective practices used by student presenters:

\section{1) Getting Audience to Participate--Encouraging questions:}

Asking and answering questions is an important mechanism for learning and a central orally-based activity in student teaching sessions. However, many students are reluctant to either pose or respond to questions orally in front of a whole class, preferring to ask 'private' questions after class, use discussion boards and/or question boxes. With this issue in consideration, through a research project conducted collaboratively between Brunei University and Universidade de Aveiro, Portugal, Watts (2007) sought to:

a) "Explore learners' 'questioning styles' and approaches to asking questions;

b) Develop 'teaching for questioning' to encourage question asking and to build this into the fabric of sessions and course provision." Watts (2007) offered explanations as to why students don't ask questions, which can be summarized as follows:

- learners do have questions but often avoid asking them

- they fail to be stimulated to ask questions

- "conceptual avoidance (the Ostrich Principal) (the Construction of Ignorance)"

The design of teaching and learning can limit and inhibit student questions

- they may experience feelings of social exposure and vulnerability

- the nature of the subject area can impact on question asking

Based on this research project's findings Watts (2007) drew a number of conclusions:

- $\quad$ "it is clearly possible to create a 'questioning environment' where asking questions (and receiving answers) becomes an integral part of everyday transactions between teachers and students;

- different strategies, such as group based mini projects, can promote questioning during sessions and enhance, more than others, the students' 'spirit of enquiry'

- teacher centered strategies, such as standard lectures, do not easily motivate students to question during the class;

- students need time and encouragement to ask higher level (higher quality) questions;

- it is clearly possible to assess question asking and answering against explicit criteria

- students need explicit formative guidance on the quality of their questions during routine teaching sessions

- students need explicit guidance and practice in the writing of questions for formative assessment

- to do so is to encourage the asking of higher level, higher quality questions which reflect conceptual clarity and critical thinking" 


\section{2) Identify and state the purposelobjective(s) of the presentation:}

Like any academic project, before conducting oral presentations students must prepare and plan for it. Study guides and skill packs encourage students to do this. Young (1998) and Drew and Bingham (2001), for example, emphasize the need to identify the objective of the presentation, allowing reflection on its purpose, aim and eventual outcome. If working in a group, at this point it may be useful to negotiate and allocate responsibilities between group members (Drew and Bingham, 2001). Next, "the students must be sure that they are familiar with the background of the information they discuss ..." (Eisen, 1998:4). In order to ensure students are familiar with the background and any current issues concerning the topic of their presentation, they are encouraged to carry out research by using textbooks, TV/films on the subject, the internet and other media (Drew and Bingham, 2001; Eisen, 1998).

\section{3) Read--Consider your audience:}

Levin and Topping (2006) suggest that consideration of the audience is vital when preparing for an oral presentation. They provide five key questions which aim to guide students on the content of their presentation, depending on their audience:

1. Who will be the audience, and why will they be there?

2. Why does your audience need this presentation, about this subject?

3. What does your audience already know?

4. What kind of energy, on your part, will be appropriate to your audience?

5. What 'protocols' will you be expected to follow? (Levin and Topping, 2006: 36)

\section{4) Plan--Organize the structure:}

Once these questions have been answered, students are encouraged to structure their presentations in a clear and coherent manner (Cottrell, 1999; Bryan, 2001; McCarthy and Hatcher, 2002; Levin and Topping, 2006). Blundel (2004) introduces the concept of rhetoric and identifies the ingredients that make a presentation persuasive and convincing; ethos, logos and pathos. Here, the use of sign posting is recommended, as it should "help the audience to know 'where they are' from moment to moment, and 'where they are going"' (Levin and Topping, 2006: 60). Levin and Topping quote a popular method which simplifies the process that a successful presentation must adopt:

\section{Tell them what you're going to tell them.}

Then tell them.

\section{Then tell them what you've told them.(Levin and Topping, 2006: 59)}

\section{5) Practicing--Rehearsing:}

Prior to the actual 'performance' rehearsing the presentation is advised (Turk, 1985; McCarthy and Hatcher, 2002 and Levin and Topping, 2006). McCarthy and Hatcher (2002) describe the usefulness of recording the presentation in an audio format, correcting mistakes or amending material or behavior before video recording it in order to further critically assess one's own performance. Turk (1985), on the other hand, highlights the advantage of using a close personal friend to 'try out' the presentation, as they are more likely to be honest and correct in their evaluation than the presenter will be of themselves. Rehearsing the presentation provides a good opportunity to assess and practice timekeeping skills, effective body language, such as eye contact and hand gestures, voice projection (or the lack of) and content (Young, 1998; McCarthy and Hatcher, 2002, Murray, 2003 and Levin and Topping, 2006). Levin and Topping (2006) offer techniques for developing the voice, the presenters' most valuable tool, including enunciation exercises and ideas for experimenting with different tones. Bryan (2001) offers useful tips in relation to voice control, pausing and repetition and McCarthy and Hatcher (2002) also provide their readers with questions concerning volume, emphasis, rhythm, pace, pitch, etc. which speakers could consider and reflect upon before or even during their presentation.

\section{6) Projecting Self-Confidence--Overcoming performance anxiety:}

Much of the literature and self-help books dealing with presentations have been generated by the fear of public speaking. This problem is so pervasive that it has produced hundreds of books and articles on the topic. As recognized earlier in this literature review, nervousness and stress may hinder one's ability to present an oral presentation to the best of their ability. For this reason, many writers have stressed the importance of practicing relaxation techniques, or adopting other approaches to ensure presenters are calm and focused before presenting 
(Turk, 1985; Bryan, 2001; McCarthy and Hatcher; 2002; Levin and Topping, 2006). Bryan (2001) for example, provides guidelines for students to follow before presenting, which include visualizing yourself performing well, taking deep breaths, clearing your mind as a way of Relaxing and releasing tension through isometric exercises (Bryan, 2001: 1145). Levin and Topping (2006) recommend techniques which are more orientated towards realizing a positive mental attitude, focusing on self appreciation and gaining a positive outlook towards the work you have accomplished, while McCarthy and Hatcher (2002: 50142) give details of specific physical exercises to aid relaxation and breathing.

\section{7) Using nonverbal cues and communication:}

The effective use of body language during an oral presentation is central to guidance for presenters. Bryan (2001) identifies particular gestures which help convey messages of authority, confidence, and trust, such as open arm gestures and finger movements (to count point 1, 2, 3, for 11 examples). Similarly, McCarthy and Hatcher, dedicate a verbal language' (2002: 107134), discussing nonverbal communication behavior which portray confidence, such as posture. Turk also dedicates a chapter to 'Nonverbal communication' (1985: 145166), and advises consideration of factors such as dress signals, posture, positioning, movement, maintaining eye contact with the audience and hand gestures.

\section{8) Handling Questions and Objections:}

Finally, presenters are advised to include a question and answer session at the end of their presentation to help clarify points, as well as providing the audience with a chance to test the knowledge of the speaker (Turk, 1985; Young, 1998; McCarthy and Hatcher, 2002; Levin and Topping, 2006). While Levin and Topping (2006) give their readers' advice on how best to manage the session, McCarthy and Hatcher (2002) give tips on how to handle questions when they are asked.

The Use of Self and Peer Assessments:

In the present study, several methods were used to rate the presenters. These included peer, audience, expert and self-ratings of presentation skills, behaviors and effectiveness. There is a growing body of research around the benefits and validation of self and peer assessment. With regard to the assessment of oral presentations skills, Magin and Helmore (2001) found that the reliability of summative assessment could be improved by combining teacher evaluation with the average from multiple peer ratings. Hughes and Large (1993) found that individuals could make reasoned assessment of their peers independently of their own ability. Baud (1989), however, argues that student assessment is too unreliable to count for summative assessment. It is also claimed that if peer assessment is only used formatively students will not take it seriously (Swanson, 1991, cited in Magin and Helmore, 2001).Unfortunately, after reviewing over 500 research studies we were not able to find any studies that related to the use or accuracy or executive, audience, expert or self-ratings of executive presentation skills, behavior or practices.

Academic and Professional Assessment of Communication Skills

It is widely accepted that business management and business educators perceive communication skills as highly valuable to employees and organizations alike. In business organizations, numerous sources have reported that communication skills are critical to career success and a significant contributor to organizational success (Du-Babcock, 2006; Roebuck, 2001; Certo, 2000; Dilenschneider, 1992; Rushkoff, 1999). In academia, research has shown faculty and administrators perceive that communication skills are very important to students' eventual career success (National Association of Colleges and Employers, 2001; Gray, 2010). Maes, Weldy, and Icenogle (1997) found that oral communication was one of the top three competencies needed to succeed in a managerial position. Yet other studies over decades have demonstrated the unsatisfactory oral communication skills of recent graduates (Bolt-Lee \& Foster, 2003; Reinsch \& Shelby, 1997). Thus, it appears that preparing students' oral communication skills for the managerial workplace has not been highly successful. Several studies reveal that business needs communication skill competency and that business education must be sensitive to and understand the communication skill needs of business. Accordingly, some evidence exists, that there are significant differences between the types of communication skills business considers important and those college instructors and business educators consider important.

\section{Study Objectives}

The objective of our study was to identify those behaviors and practices that are associated with self, peer, audience and expert evaluations used by managers and executive who rated as highly effective presenters. As a result of our research, we developed a 35-item executive presentation practices that we refer to as the "Presenter Assessment Inventory", or PSI. This development of this instrument was based on a thorough review of the literature on oral 
communication skills, effective organizational and business communication practices and extensive interviews with senior executives and experts in management, communication, and behavioral research. We initially identified over 200 item or practices. However, we were able to reduce the number of items to the final set of 35 items that were most frequently and consistently identified as behaviors that were used by outstanding business presenters and presentations. In the present study, we provided executives giving a 90 minute presentation with two types of audience feedback about the practices that were demonstrated in their presentations: 1) the frequency or "how often" they demonstrated or used specific practices or skills and 2) the level of skill or ":effectiveness": that the presenters demonstrated during their presentations. The PSI enables the business presenters to compare their self-perceptions of the skills and practices that they use and the impressions or "impact" they make on the audience with audience assessments of their behavior.

Structure of this Report

Our research is organized into 4 sections:

A review of the process and statistical methods that were used to select items that were included in the PSI;

1) A review of the statistical methods that were used to determine the reliability and internal consistency of items or presentation practices and the items associated with several presentation skill clusters;

2) Present a review of the psychometric properties of the PSI clusters including the reliability of the major constructs that serve as the basis for measuring presentation practices;

3) Finally, a set of multivariate regression analyses was used to determine the relative $\%$ of variance explained by each of the 5 presentation skill clusters and the overall ratings of the presenter's communication style and effectiveness.

\section{Methodology}

\subsection{Statistical Methods}

We performed a descriptive analysis (frequencies and percentages) of the demographic characteristics of the participants. We conducted factor analysis develop clusters for items showing a high level of commonality. Prior to conducting the factor analysis, we tested the suitability of the presentation skill rating scale using the Kaiser-Meyer-Oklin (KMO) test and the Bartlett's Test of Sphericity. Because the some of the data was skewed toward the higher values, we re-categorized the answer choices into three groups: "poor or fair," "good," and "very good or excellent."

We then conducted a series of analyses to evaluate the psychometric properties of the PSI survey questionnaire. We measured internal consistency reliability (Cronbach's alpha) to assess whether all the items were contributing to the measurement of presentation practices, we also measured inter-item gamma scores to examine the level of relationship between the items in the questionnaire and calculated correlation coefficients for items in each cluster. In addition, we calculated the Kruskai-Wallis K Independent Samples test to examine differences in total score across demographic groups. The total score was computed by tabulating the sum of all 35 items to provide a continuous measure of presentation skills. We used SPSS version 13.0 (SPSS, Inc., Chicago, Illinois) for all analyses.

\subsection{Development of the PSI Research Instrument}

Three methods were used to develop the 35 items and 5 clusters of the Presentation Skills Inventory (PSI) questionnaire used in our research. As mentioned previously, an extensive review of behavioral science research studies was used to identify those skills, characteristics and practices used by outstanding business presenters. This review included over 500 technical documents, research reports and evaluations published during the past 30 years. A group of 40 trained content analysis evaluators who were not familiar with the research literature or the content of the questionnaire. The content reviewers analyzed the results of these research studies and initially recorded over 150 items or practices used by effective business, government and industry presenters. After rewording, editing and consolidating these items, 52 presentation practices were used in the research instrument. This set of practices was then evaluated by a second group of reviewers consisting of 35 executives, consultants, psychologists, trainers and highly experienced public speakers. The judgments of this group were based on over 10,000 presentations that they had conducted, attended or evaluated. After each of the items 52 practices were evaluated, a set of 40 were included in the pilot study. Thirty five senior executives used these practices to evaluate the effectiveness of a 90 minute, financial services presentation. After completing their assessments, the practice items were reworded to reduce overlap and improve comprehension. The data gathered during this pilot was analyzed and practice items that either had a low completion rate or very little variance were eliminated from the practices instrument. This resulted in a set 
of 35 items that we used in our study.

\subsection{Ratings of Presenter Effectiveness and Use of Presentation Practices}

The 35 item Presentation Practices Inventory (PSI) was completed by 250 business executives who attended a 5 hour financial services education program. Several different statistical methods were used including an ANOVA to evaluate the reliability and internal consistency of the practices and presentation clusters used in the PSI. We also evaluated the degree to which the raters using the PSI varied in their ratings of the presenters. Statistics revealed that ratings of "Frequency of Use" of presentation practices ranged from 3.2 to 4.4. Ratings of "Presenter's Skill Level" ranged of 3.7 to 4.5 on a five point Likert Scale. The standard deviation 0.71 to 1.03 indicating a significant variation in ratings of these sets of practices The audience was asked at the end of the questionnaire to rate the Overall Effectiveness of the Presenter. This set of practice ratings ranged from 3.0 to 4.4 ; the average rating was 3.8/5.0 with a standard deviation of .82. These statistics suggest that there was a significant amount of variation in the audience evaluation of the 35 presentation practices used by the presenters in our study.

\subsection{Cluster Analyses}

Cluster analysis of the ratings of 250 executives who completed the Presentation Practices Inventory revealed 10 presentation practice factors or "clusters. ANOVA was used to explore the correlations between practice ratings and presentation skill factors. There were two categories of factors that demonstrated the best-fit between practices and factors.

\section{a) Frequency of Use Clusters}

The first set of questions asked the audience (presentation evaluators) to rate each presenter in terms of how often he/she used the five types of presentation skills, practices and behaviors in his/her interaction with them. The following Frequency of Use Clusters resulted from our analysis of the data:

1) Establishing Credibility and Authority consisted of 7 practices, $r$ ranged from +.25 and +.50 , The overall Average internal consistency of items in this cluster $=$ RFic $1 .=+.81$

2) Maintaining Focus consisted of 7 practices, $r$ ranged from +.40 and +.76 , The overall internal consistency of items in this cluster $=$ RFic $2 .=+.88$

3) Building a Positive Environment consisted of 9 practices, $\mathbf{r}$ ranged from +.25 and +.70 , The overall-Average internal consistency of items in this cluster $=$ RFic3. $=+.90$

4) Delivering a Useful/Effective Presentation consisted of 4 practices, $r$ ranged from +.44 and +.80 , The overall-Average internal consistency of items in this cluster $=$ RFic4. $=+.81$

5) Impact-Promoting Retention consisted of 8 practices, $r$ ranged frorn +.25 and +.85 , The overall-Average internal consistency of items in this cluster $=$ RFic5.=+.81

These results (See Table\#1) indicate that all 5 of the frequency of use presentation practices had moderate to high correlations between component practices and overall cluster scores. Internal consistency coefficients for Frequency of Use Clusters were high ranging from $\mathrm{r}=+.81$ to .90 .

\section{b) Presenter Skill-Level Clusters}

A similar pattern was found when we analyzed the 35 questions that focused on the audiences' evaluation of the presenters' skill level as demonstrated by five different presentation skill clusters. The results of our analysis of the 5 Presentation Skill Level Clusters as shown below:

1) Presenters' Skill in Establishing Credibility and Authority consisted of 7 practices were moderately correlated-- $\mathrm{r}$ ranged from +.30 and +.57 . The overall Average internal consistency of items in this cluster $=$ the internal consistency for this cluster RSic1. $=+.81$ was statistically significant.

2) Maintaining Focus consisted of 6 practices, correlations for these items ranged from +.42 and +.76 , The overall internal consistency of items in this cluster $=$ RSic2. $=+.82$

3) Building a Positive Environment consisted of 9 practices, $r$ ranged from +.27 and +.75 , The overall-Average internal consistency of items in this cluster $=$ RSic $3 .=+.89$

4) Delivering a Useful/Effective Presentation consisted of 4 practices, $r$ ranged from +.27 and +.56 , The overall-Average internal consistency of items in this cluster $=$ RSic4. $=+.76$

Impact-Promoting Retention consisted of 9 practices, $\mathrm{r}$ ranged from +.27 and +.79 , The overall-Average internal consistency of items in this cluster $=$ RSic5. $=+.88$ 
These results (See Table\#2) indicate that all 5 of the presenter skill-level practices had moderate to high correlations between component practices and overall cluster scores. Internal consistency coefficients for Frequency of Use Clusters were high ranging from +.76 to .89 .

\section{Results Summary: Frequency of Use Clusters}

As Table\#3 indicates there was a moderate to high degree of inter-correlation between the five Frequency of Use Clusters were high ranging from $r=+.66$ to .77 . This indicates that there was a positive, significant $(+.0001$ level of significance between the 5 frequency of use clusters, Cluster 5, Promoting Retention was most highly correlated with the four other frequency clusters ( $\mathrm{r}=+.60$ to .77 ). There was a moderate relationship between Maintaining Focus and Establishing Credibility and Authority $(\mathrm{r}=+.50)$ and with Building a Positive Environment $(\mathrm{r}=+.48)$. There was also a strong relationship between ratings of Establishing Credibility and Authority and Building a Positive Environment $(\mathrm{r}=+.70)$. The correlation between these two clusters and ratings of overall Presenter Effectiveness was $r=+.69$. One interpretation of these results is that presenters who exert more authority are seen by the audience (evaluators) as Promoting a More Positive Environment and the more likely they are to retain information and/or derive benefit from the presentation. Presenters who establish their Authority and Credibility are seen as more effective presenters.

\section{Results Summary: Presenters' Skill Level Clusters}

As table\#4 indicates, correlations between the five presentation skill clusters range from +.55 to .75 . While, the range of correlations for skill clusters were slightly lower than the frequency of use correlations, the general pattern and direction of these correlations were found to be quite similar. Audience ratings of Promoting Retention were most highly correlated with ratings of Presenter Effectiveness $(\mathrm{R}=+.76)$ and skill in Creating a Positive Environment $(\mathrm{r}=+.73)$.There was a moderate relationship Creating a Positive Environment and Establishing Authority and Credibility $(\mathrm{r}=+.73)$. There was a much lower relationship between the Maintaining Focus MF Cluster and the Establishing Authority and Credibility EAC Cluster $(\mathrm{r}=+.53)$. There was also a somewhat lower relationship between each of these 2 clusters (MF and EAC) and overall ratings of Presenter Effectiveness $(r=+.50)$. These findings suggest that presenters who focus on Promoting Retention are rater higher on Presenter Effectiveness as compared to those who place more emphasis on Establishing Authority or Maintaining Focus. On the other hand, presenters who Establish Authority are seen as Creating a more Positive Environment. All of these correlations were positive and significant ( $\mathrm{p}=.0001)$ indicating a high degree of consistency in audience evaluation of the presenters skills and behaviors.

\section{Relationships between Ratings of Presenter Effectiveness and How Frequently Practices Were Used}

As table\#5 indicates, as we might expect intuitively, the audience rated presenters who exhibited greater use of presentation practices to be more effective; the reverse pattern was also observed. Correlations between the 5 frequency of clusters and the ratings of the 5 effectiveness clusters were significantly inter- correlated ( $\mathrm{r}=+.79$ to. 90$)$. The strongest and most significant relationship were between audience ratings of the skills and frequency of practices used by presenters to Create a Positive Environment ( $\mathrm{r}=+.90)$ and between ratings (skills and frequency) that were used by presenters to Maintain Focus (keeping the audience focused) $r=.+89$. There was a moderate relationship $(\mathrm{r}=+.79)$ in terms of Establishing Control and Authority. Perhaps this suggests that presenters are too controlling are seen as less effective by the audience. However, the overall pattern across all 5 presentation practice clusters strongly suggests that audience perceptions of the presenters' effectiveness were significantly related to how frequently they used the practices.

\section{Relationships between Presentation Practice Ratings and Audience Evaluations of Presenter Effectiveness}

Significant relationships were found between audience evaluation of Presenter Effectiveness (skill in dealing with questions, responding to challenges/disagreement and facilitating two-way discussion/interaction with the audience) and audience ratings of the Frequency of Practices across all 5 clusters $\mathrm{P}=+.001$ ). Correlations between Presenter Evaluations and ratings on Frequency of Use clusters show a moderate degree of variation ( $r=+32$ to .69). The strongest relationships between audience ratings of the Building a Positive Environment and evaluations of the 4 items of the presenter's ability to manage the audience ( $\mathrm{r}=+57$ to .69$)$. This finding suggests that presenters who Create a Positive Environment during their presentations, are seen by the audience as more effective presenters. The relationships found between the remaining 4 Frequency of Use Clusters and audience evaluations of presenter effectiveness ranging from a lower and less significant ( $\mathrm{r}=.+50$ to .60$)$ for the Establishing Control and Authority, from r=.+32 to .47 for Maintaining Focus, from r $=.+48$ to .52 for Delivering a Useful Presentation and from $\mathrm{r}=+.53$ to .56 for Promoting Retention. Based on these findings, it appears that the Presenters' ability to Create a Positive Environment has a greater impact on audience evaluations of the presenters' effectiveness than the other 4 
presentation practice clusters.

As the data presented in table 6 indicate, a similar results were observed for the ratings of the 5 Presentation Skill Clusters and audience evaluations of Presenter Effectiveness ( $r=.+35$ to $.71 ; p=+.001)$. The strongest relationships between audience ratings of the skills used to Build a Positive Environment and evaluations of the 4 items of the presenter's ability to manage the audience ( $\mathrm{r}=.+64$ to .71 ). Again, audience ratings of Maintaining Focus and Presenter Effectiveness Evaluations were significant but showed the level of relationship ( $\mathrm{r}=+.35$ to .46). Establishing Control and Authority were significantly related to each of the 4 Presenter Effectiveness Evaluations. The strongest relationships were found between this cluster and Managing Conine! (disagreement) $r=+70$, and Facilitating Audience Discussion- Participation $(\mathrm{r}=+.68)$. We also found that there was a weak relationship between Audience Evaluations of the Presenters' ability to Manage Conflict and ratings of the Maintaining Focus cluster $(\mathrm{r}=+.33)$. This finding might suggest that "keeping the presentation on track" by failing to address issues and/or ignoring confnct or resistance is not seen positively by the audience. This has important implications; an effective presenter has to be able to "read the audience" and deviate from his/her plan when important issues are raised by the audience. Executive presenters who demonstrated Skill in Establishing Credibility, Creating a Positive Environment and Promoting Retention received much higher evaluations of their effectiveness in Managing Conflict/Resistance. This pattern was not related to the Frequency of Use of practices for these 3 clusters.

\section{Relationships between Audience Ratings of Skill and Frequency Clusters and Audience Evaluation of the Presenters' Overall Effectiveness}

The audiences' overall ratings of the presenters' effectiveness was assessed using two different measures. The final question asked the evaluator to give each presenter an Overall Effectiveness Performance Rating (OEPR) during his/her 5-hour presentation. We also measured presenter effectiveness by calculating the weighted average of the 4 different presenter ratings of executive presenters in our study. We refer to this measure of the presenter's effectiveness as the Combined Average Effectiveness Score (CAES). As table 7 indicates, there were strong positive correlations between these two measures (OEPR and CAES) and executive presentation practices. Correlations between overall ranged from $\mathrm{r}=+.55$ to +.89 for Frequency of Practice Use and from +.60 to +.89 for Presenter Effectiveness. There were strong, positive and significant relationships found between the audience's overall effectiveness ratings (OEPR) and the frequency of using the following practices: Building a Positive Environment, $\mathrm{r}=+.70$; Promoting Retention, $\mathrm{r}=+, 69$; and Establishing Credibility/Authority, $\mathrm{r}=+.66$. Maintaining focus showed the lowest correlation with Audience OEPR ratings $(\mathrm{r}-=+.55)$. As expected, the same trends were in general found between the Combined Audience Performance Scores (CAES). However, ratings of OEPR and Promoting Retention had the highest degree of relationship ( $\mathrm{r}=+.89$ ); all of these findings were significant at the +.001 level).

The frequency of use of practices that focused around Building a Environment were significantly related to CAES, $\mathrm{r}=+.8 ; \mathrm{p}=+.001$. Alternatively, presenter skill in Establishing Credibility and Authority and Building a Positive Environment correlated with CAES ( $\mathrm{r}=+.+76$ and $\mathrm{r}=+.74$ respectively. When CAES was used as an indicator of presenter effectiveness, skills associated with Promoting Retention, $(\mathrm{r}=+.89)$, Establishing Authority and Building A Positive Environment were highly correlated $(r=+.86) \mathrm{p}=.0001$. Skill in Promoting Retention was more highly related to CAES than OEPR.

Multiple regression analysis was used to determine how much variance in ratings of presenter performance was accounted by each of the presenter practice and frequency of use clusters. Three separate, step-wise MOVA analyses were conducted. The use of step-wi se regression takes into account both the independent contribution or weighting of each cluster score from the score that accounts for the most variance in presenter ratings to the clusters that account for little or no variance. In addition, at each 'step in the analysis, weighted coefficient express the relative or comparative amount of explained variance in ratings attributed to each of the cluster scores.

\section{References}

Atkinson, C. (2005). Beyond Bullet Points: Using PowerPoint to Create Presentations that Inform, Motivate, and Inspire. New York: Microsoft Press.

Bienvenu, S. (1999). The Presentation Skills Workshop. New York: American Management Association.

Bloxham, S., \& West, A. (2004). Understanding the rules of the game: marking peer assessment as a medium for developing students' conceptions of assessment. Assessment and Evaluation in Higher Education, 29(6), 721-733.

Blundel, R. (2004). Effective Organizational Communication. Essex: Prentice Hall. 
Booher, D. (2002). Speak with Confidence: Powerful Presentations that Inform, Inspire and Persuade. New York: The McGraw-Hill.

Boud, D. (1989). The role of self-assessment in student grading. Assessment and Evaluation in Higher Education, 14, 20-30.

Bradbury, A. (1996). Successful Presentation Skills. New Delhi: Kogan Page India Limited.

Brookfield, S. D., \& Preskill, S. (1999). Discussion as a Way of Teaching, Tools and Techniques for University Teachers, Buckingham: SRHE \& Open University Press Brunei University, (2007) Oral Communication Skills. Retrieved 3 April 2007, from http://www.brunel.ac.uk/life/studylltdu/bold/oralcommunication

Bryan, C. (2001). Presenting your case. In Stott R, Young T, and Bryan C. (Eds.), Speakin Your Mind, Oral Presentation and Seminar Skills. England: Pearson Education Ltd.

Carnegie, D. (1976). How to Develop Self-Confidence \& Influence People by Public Speaking. New York: Simon \& Schuster Adult Publishing Group.

Carnegie, D., \& Carnegie, D. (1977). The Quick and Easy Way to Effective Speaking. New York: Pocket Books.

Conrad, D., \& Newberry, R. (2011). 24 Business Communication Skills: Attitudes of Human Resource Managers versus Business Educators. American Communication Journal, Spring, 13(1).

Cordell, W. H. (2005). Preparing a Presentation and Developing Speaking Skills. Society for Academic Emergency Medicine. Retrieved 17 October 2005, from http://www.saem.org/publicatlchap8.htm

Cyphert, D., Worley, R., \& Dyrud, M. (2002) Integrating communication across the MBA curriculum. Business Communication Quarterly, 65(3), 81-86.

Detz, J. (2000). It's Not What You Say; It's How You Say ft. New York: St. Martin's Press.

Dilenschneider, R. L. (1992). A briefing for leaders: Communication as the ultimate exercise of power. New York, NY: HarperCollins.

Diresta, D. (1998). Knockout Presentations: How to Deliver your Message with Power, Punch, and Pizzaz. Worcester, MA: Chandler House Press.

DiStanza, J.R., \& Legge, N.J. (2002). Business and Professional Communication. Boston, MA, Allyn and Bacon.

Dowis, R. (1999). The Lost Art of the Great Speech. New York: American Management Association.

Du-Babcock, B. (2006). Teaching business communication: Past, present, and future. Journal of Business Communication, 43(3), 253-264.

Eisen, A. (1998). Small group presentations- teaching "science thinking" and context in a large biology class. Bioscience, 48(1), 53-59.

Exley, K., \& Dennick, R. (2004). Small Group Teaching, Tutorials, Seminars and Beyond. USA: Routledge Falmer.

Fordham, D., \& Gabbin, A. (1996). Skills versus apprehension: Empirical evidence on oral communication. Business Communication Quarterly, 59(3), 88-97.

Gaulke, S. (1996). 101 Ways to Captivate a Business Audience. New York: American Management Association.

Hanna, M., \& Wilson, G. (1998). Communicating in business and professional settings. New York, NY: The McGraw-Hill Companies.

Hughes, I.E., \& Hynes, G. (2005). Managerial communications: Strategies and applications. New York, NY: McGraw-Hill/Irwin.

Hybels, S., \& Weaver, R. L. (2004). Communicating Effectively. New York: McGraw-Hill.

Jacobi, J., \& Randall, T. (2000). How to Say It with Your Voice. New Jersey: Prentice Hall.

Jeary, T. (2003). Life is a Series of Presentations. New York: Simon \& Schuster Adult Publishing Group.

Joughin, G. (1998). Dimensions of oral assessment. Assessment \& Evaluation in Higher Education, 23(4), 367-378.

Joughin, G., \& Collom, G. (2003). Oral assessment. The Higher Education Academy. Retrieved 3 April 2007, from www.heacademy.ac.uk/embedded_object.asp?id=21642\&filename=Joughin_and_Co11om

Kalish, K. (1997). How to give a terrific presentation. New York: American Management Association.

Kaye, E., Kaye, E. A., \& Devillers, J. (2002). Maximize Your Presentation Skills. New York: Crown Publishing 
Group.

Large, B.J. (1993). Staff and peer group assessment of oral communication. Studies in Higher Education, 18(3), 379-385.

Leech, T. (2004.) How to Prepare, Stage, and Deliver Winning Presentations. New York: American Management Association.

Levin, P., \& Topping, G. (2006). Perfect Presentations! Berkshire: Open University Press.

MacAlpine, J.M.K. (1999). Improving and encouraging peer assessment of student presentations. Assessment and Evaluation in Higher Education, 24(1), 15-25.

Maes, J. D., Weldy, T. G., \& Icenogle, M. L. (1997). A managerial perspective: Oral communication competency is most important for business students in the workplace. The Journal of Business Communication, 34(1), 67-80.

Magin, D., \& Helmore, P. (2001). Peer and teacher assessments of oral presentation skills: how reliable are they? Studies in Higher Education, 26(3), 287-298

Mandel, S. (1999). Effective Presentation Skills: A Practical Guide for Better Speaking. Stanford, CT: Thomson Crisp Learning.

Maruffi B. L., Petri W.R., \& Malindretos, J. (2013). Corporate Social Responsibility and the Competitive Advantage of Multinational Corporations: What is the Right Balance? Culture and Competitive Advantage. Journal of Global Business Issues, (2), Fall, 69-81.

McCarthy, P., \& Hatcher, C. (2002). Presentation Skills, the Essential Guide for Students. London: Sage Publications Ltd.

McCarthy, P., \& Hatcher, C. (2002a). Giving Presentations: An essential guide. London: Sage.

McCarthy, P., \& Hatcher, C. (2002b). Speaking Persuasively: The Essential Guide to Giving Dynamic Presentations. Sydney: Allen Unwin.

Mortensen, K. W. (2004). Maximize Influence. New York: American Management Association.

Murphy, H., Hildebrandt, H., \& Thomas, J. (1997). Effective Business Communications. New York, NY: McGraw-Hill/Irwin.

Murranka, P. A., \& Lynch, D. (1999). Developing competency-based fundamentals of management communication course. Business Communication Quarterly, 62(3), 9-23.

Pappas and Hendricks. (2000). Holistic Grading in Science and Engineering. Journal of Engineering Educ., 89, 1-13.

Peoples, D. A. (1992). Presentations Plus: David Peoples' Proven Techniques. Indianapolis: Wiley.

Pfarrer, D. (1998). Guerrilla Persuasion: mastering the art of effective and winning business presentations. New York: Houghton Mifflin Company.

Pittenger, K. K. S., Miller, M. C., \& Molt, J. (2004). Using real-world standards to enhance student's presentation skills. Business Communication Quarterly, 67(3), 327-336.

Pope, N.K. (2005). The impact of stress in self and peer assessment. Assessment and Evaluation in Higher Education, 30(1), 51-63.

Reinsch, L., \& Shelby, N. (1997). What communication abilities do practitioners need? Evidence from MBA students. Business Communication Quarterly, 60(4), 7-29.

Rotondo, J., \& Rotondo, M. (2001). Presentation Skills for Managers. New York: McGraw-Hill.

Sampson, E. (2003). Creative Business Presentations: inventive ideas for making an instant impact. London; Sterling, VA: Kogan Page.

Seshadri, S., \& Theye, L. D. (2000). Professionals and professors: Substance or style? Business Communication Quarterly, 63(3), 9-23.

Smith, K. (2006). Do we know what we are looking for in student oral presentations ...and how can we help them achieve it?. Presented at LDHEN Symposium, Liverpool Hope University, April 2006.

Stevenson, D. (2003). Never be boring again: make your business presentations capture attention, inspire action, and produce results. Colorado Springs: Cornelia Press. 
Stott, R. Young, T., \& Bryan, C. (2001). Speaking Your Mind. Oral Presentation and Seminar Skills. England: Pearson Education Ltd.

Tisdale, J. J. (2005). Effective Business Presentations. New Jersey: Pearson/Prentice Hall.

Tubbs, S. L., \& Moss, S. (2002). Human Communication: Principles and Contexts. New York: McGraw-Hill.

Turk, C. (1985). Effective Speaking, Communicating in Speech. London: Chapman \& Hall.

Ulinski, M., \& O'Callaghan, S. (2002). A comparison of MBA students' and employers' perceptions of the value of oral communication skills for employment. Journal of Education for Business, 77(4), 193-197.

Villata, E. (2003). Helping Professionals Prepare Presentations in English for International Conferences. English Language Teaching Forum, 1. Retrieved 18 October 2005, from http://exchangesstate.gov/forum/vols/vol41/no1/p30.htm

Waner, K. (1995). Business communication competencies needed by employees as perceived by business faculty and business professionals. Business Communication Quarterly, 58(4), 51-56.

Weissman, J. (2003). Presenting to win: the art of telling your story. New York: Financial Times Prentice Hall.

Wempen, F. (2004). PowerPoint Advanced Presentation Techniques. Indianapolis: Wiley. Wilder, C. (1994). The Presentations Kit: 10 Steps for Selling your Ideas. New York: Wiley.

Wiersma, K., \& Jansen, P. (2004). Speaking in Public. Pearson Education.

Witherspoon, R., \& White, P. (1997). Four Essential Ways that Coaching Can Help Executives. Greensboro, North Carolina: Center for Creative Leadership.

Yamashiro, A. D., \& Johnson, J. (1997, April). Public Speaking in EFL: Elements for Course Design. The Language $\begin{array}{lllll}\text { Teacher } & \text { Online. } & \text { Retrieved } & \text { October } & \text { 2005, from }\end{array}$ http:/lwww.jalt-publications.org/tl!!files/97/apr/yamashiro.htmI 